\title{
Representação social da violência: estudo exploratório com estudantes de uma universidade do interior do estado de São Paulo
}

\section{The social representations of violence: an exploratory study of undergraduate students from a university in the countryside of Sao Paulo state}

\author{
Adriana Leonidas Oliveira ${ }^{1}$ \\ Edna Maria Oliveira Querido Chamon² \\ Aline Gomes Cazarim Mauricio 3
}

\begin{abstract}
RESUMO
O estudo das Representações Sociais é um importante recurso metodológico de conhecimento dos fenômenos do cotidiano. Seu objetivo é abstrair sentido do mundo e introduzir nele ordem e percepções. O tema violência é uma reflexão antiga no Brasil, e necessita a todo tempo ser problematizado. O espaço acadêmico é um meio propulsor de se construir representações mais autênticas, desmistificando aquelas que não favorecem o desenvolvimento humano. Esse estudo teve como objetivo levantar as representações sociais da violência entre universitários de uma universidade do interior do Estado de São Paulo. Foram realizadas vinte entrevistas com estudantes das áreas exatas, humanas e biológicas, analisadas qualitativamente com
\end{abstract}

1 Doutora em Psicologia Clínica pela PUC-SP, Professora Assistente da Universidade de Taubaté, pesquisadora do Núcleo de Estudos sobre Violência e Criminalidade da Universidade de Taubaté.

2 Doutora em Psicologia Social pela Universidade de Toulouse II, França, Professora Assistente da Universidade de Taubaté, coordenadora do Núcleo de Estudos sobre Violência e Criminalidade da Universidade de Taubaté.

3 Estudante do $5^{\circ}$ ano de Psicologia-bolsista-PIBIC/CNPQ-2007-2008 - Universidade de Taubaté - UNITAU 
auxílio do software Alceste. Os resultados apontaram duas classes de representação da violência: Perspectiva social e política e Perspectiva Familiar. Os estudantes que têm suas representações fundamentadas em aspectos da esfera social parecem estruturá-las percebendo o quanto o indivíduo é afetado pela dinâmica social e política, percebendo a violência como fruto do desamparo do Estado, dos prejuízos do sistema capitalista que geram desigualdades sociais. Na perspectiva Familiar os estudantes perceberam mais as manifestações da violência física e psicológica, as quais remetiam a elementos como falta de amor, desestruturação familiar, violência doméstica. Estudantes das três áreas incluem o fator social como produtor da violência. Conclui-se que as representações sociais dos estudantes sugerem uma apropriação do saber científico, havendo proximidade de raciocínio entre os estudantes da mesma área.

Palavras-chave: representação social; violência; estudantes universitários.

\begin{abstract}
The study of social representations is an important methodological resource in gathering daily phenomena knowledge. It aims at abstracting sense from the world and introducing order and perceptions. The violence theme is an old one in Brazil, and it demands to be studied. Academia is a motivating milieu to develop more authentic social models, understand them, and open new representations, demystifying those that do not contribute to human development. This exploratory study intended to survey violence social representations among students in a University in the countryside of São Paulo. Twenty students from exact, human, and biological study fields were interviewed, and the interviews were then qualitatively analyzed using the Alceste software. The results indicate two classes of violence representation: from a social and political perspective; and from a family perspective. Students basing their representations on social aspects notice how the individual is affected by social and political dynamics, tending to perceive violence as stemming from: governmental abandonment; damages from a capitalist system engendering social inequalities; and a lack of common good policies. From a family-based perspective, students emphasized manifestations of physical and emotional violence related to lack of love, family disintegration, domestic violence, and family negligence. Students from the three study areas included both social factors as the violence source. It was concluded that violence social representations suggest scientific knowledge acquisition and there was similarity of reasoning among students from all study areas.
\end{abstract}

Keywords: social representation; violence; undergraduate students. 


\section{Introdução}

O estudo das Representações Sociais é importante como recurso metodológico de conhecimento dos fenômenos do cotidiano, que adquirem relevância entre os grupos. Ao perscrutar a abordagem de Moscovici percebe-se que as Representações Sociais oferecem ferramentas teóricas e práticas ao mesmo tempo (MOSCOVICI, 2003). Toda sociedade e a ciência procuram meios de produzir sentido e buscar transformação e o fazem também através das representações. E de acordo com Minayo (1995) as representações podem ser consideradas matéria-prima para análise do social e também para a ação pedagógico-política de transformação.

O fenômeno da violência tem sido objeto de estudo também no campo das representações sociais, dada a expansão dos índices da violência urbana e dos problemas de segurança pública que ocorrem no Brasil. Diversos profissionais, estudantes e teóricos, têm trabalhado a violência como vetor social, político e econômico, categorias do espaço público. Outros pensam a violência ligada mais a questões de valores, família, educação, que tem seus argumentos voltados ao domínio privado. A realidade é que tudo isso está ligado e corremos o risco de fragmentar os sentidos, ou de naturalizar, banalizar essa questão. A violência deve ser encarada com seriedade e urgência, e apesar de saber que é gerada historicamente, ela faz parte de um processo que hoje apresenta algumas facetas diferentes que acompanham o contexto sociocultural.

Muitos entendimentos acerca desse assunto são produzidos, outros estão cristalizados, e tantos outros necessitam ser repensados. O presente trabalho se insere nessa perspectiva, e teve como objetivo refletir sobre o que os estudantes têm pensado a respeito da violência e quais representações estão sendo construídas ou transformadas. O espaço acadêmico é um meio propulsor de se construir representações sociais mais autênticas, entendê-las, e se abrir a novas representações, desmistificando aquelas que não favorecem o desenvolvimento humano.

\section{Representações sociais}

Dentre as várias possibilidades de conceituação de representação social, uma proposta de Denise Jodelet parece útil, no sentido de indicar os elementos 
que devem ser buscados em um estudo empírico das representações sociais. A autora pontua que a representação social é "[...] uma forma de conhecimento, socialmente elaborado e partilhado, tendo uma orientação prática e colaborando na construção de uma realidade comum a um conjunto social" (JODELET, 1989, p. 36, tradução nossa). Isso sugere que a pesquisa de campo deve ser orientada para a busca dos saberes provenientes do senso comum que possuem uma orientação prática, isto é, que guiam a conduta e que são próprios à realidade do grupo estudado. Esses elementos de senso comum - opiniões, crenças, atitudes, informações - constituem o conteúdo básico da representação. Entretanto, sua estruturação e dinâmica são definidas por outros processos: a objetivação e a ancoragem.

A objetivação transforma o abstrato em concreto, o conceito em objeto, $\mathrm{e}$ os faz intercambiáveis. Assim, por meio de simplificação, descontextualização e naturalização, o objeto torna-se idêntico à sua imagem, e é apropriado pelo grupo (ELEJABARRIETA, 1996). Já a ancoragem produz o enraizamento da representação no sistema de pensamento preexistente. Ela promove a integração de um objeto novo em uma rede de categorias familiares, socialmente estabelecidas (DOISE, 1992). Dessa forma, refere-se a significações outras, que não aquelas internas ao conteúdo da representação.

Esses processos "[...] indicam a maneira como o social transforma um conhecimento em representação e como esta representação transforma o social" (JODELET, 1992, p. 367, tradução nossa). A representação social, cuja gênese é dada por esses processos, assegura estabilidade ao objeto representado. Balizando a ideia que fazemos de um mundo em constante evolução, a representação transforma "[...] o complexo em simples (objetivação) e o estranho em familiar (ancoragem)", permitindo a integração do novo e do desconhecido (CHAMON, 2007, p. 39).

\section{Violência e representações sociais}

Discutir sobre violência é uma tarefa difícil, infinita, que está relacionada com diversos aspectos que se entrecruzam. Existe um arsenal de entendimentos sobre a violência que, de certa forma, coexistem. Pode-se entender essa problemática por diversos ângulos, como o social e político, outros ligados ao universo individual, moral, psicológico. Tais entendimentos estão, portanto, interligados.

Pensando no primeiro aspecto assinalado acima, Abramovay et al (2002 apud GUARESCHI et al, 2007) mencionam três perspectivas da violência nessa dimensão: 1- a violência direta, agressividade, dano físico; 2- a violência indireta relacionada à coerção psicológica ou emocional, e 3- a violência simbólica 
que diz respeito aquela ligada a relações de poder, de dominação, que mina a consciência do indivíduo. Essa última é um tipo de violência subjacente nas relações. Como descreve Bourdieu (1999 apud SOUZA, 2007) é um mecanismo de legitimação de outras formas de violência e da constituição de uma "cultura da violência", que sustenta todas elas. As pessoas que sofrem essa espécie de violência ficam com sua consciência adormecida, subjugada por aqueles ditos mais poderosos, cerceando as possibilidades de crescimento, de melhores condições de vida do indivíduo ou de grupos. Dessa forma, não se entende a violência restrita ao espaço individual, como se o agressor possuísse uma índole má, mas sim, produzida socialmente, sendo um fenômeno social que para ser enfrentado precisará de políticas públicas, políticas educacionais, promoção de consciência e emancipação ou simplesmente o respeito ao ser humano.

A outra perspectiva desse quadro é voltada para aspectos microssociais. Explicada no plano psicológico, familiar, na perda de valores, a violência seria decorrente da desestruturação da família, ou seja, famílias agressoras ou negligentes favorecem a entrada dos filhos no caminho da violência e criminalidade. Nesse sentido, Castro et al (2001) afirmam que a violência doméstica é um elemento que atua como desencadeador da chamada cadeia de violência ou reprodução das mesmas.

Para que um objeto, ou fenômeno, se torne uma representação social é preciso que ele seja relevante, seja objeto de discussão de grupos, gere estranheza e incômodo, ou como afirma Wagner (1998 apud ANCHIETA; GALINKIN, 2006) esse objeto precisa causar mudanças na rotina e no padrão de comportamento de indivíduos ou grupos. O tema da violência, além de ser uma reflexão antiga no Brasil, atualmente emerge com grande impacto. Pode se constatar a persistência da informação pelos meios de comunicação. Por isso não é de estranhar que se tornou objeto de representação social, uma vez que mexe com o cotidiano e a intimidade das pessoas. Conforme mencionado, as representações criam a realidade porque uma vez estabelecidas passam a influenciar as interações sociais e acabam legitimando e justificando condutas, essas, muitas vezes podem estar a favor de posições ideológicas que carregam preconceitos e perpetuam discriminações. É o caso de muitos discursos transformados em representações sociais que enfatizam que a violência é gerada pura e simplesmente nas classes mais baixas e que não guardam nenhuma relação com questões sociais, políticas, não percebendo a violência simbólica subjacente a essas questões. 


\section{Método}

Quanto ao objetivo, esse estudo foi de caráter exploratório, desenvolvido por meio de abordagem qualitativa. Foram realizadas entrevistas semiestruturadas, analisadas qualitativamente, por meio de técnicas de análise de conteúdo e com o apoio do software ALCESTE®.

Participaram do estudo vinte universitários das três áreas do conhecimento (Humanas, Biociências e Exatas) de uma universidade do interior do estado de São Paulo. As características do grupo amostral podem ser visualizadas no quadro 1

\begin{tabular}{|c|c|c|c|}
\hline Curso & Biociências & Humanas & Exatas \\
\hline Idade média & 21,25 & 19,8 & 23,8 \\
\hline Sexo & 4 feminino & 6 feminino & 0 feminino \\
& 4 masculino & 1 masculino & 5 trabalham \\
\hline Trabalho & 3 trabalham & 6 trabalham & \\
\hline
\end{tabular}

QUADRO 1 - CARACTERIZAÇÃO DOS ESTUDANTES

\section{Tratamento dos dados}

Para o tratamento das entrevistas utilizou-se a análise de conteúdo, que é um instrumento de análise das comunicações. Dentre as diversas formas que a análise de conteúdo pode assumir (BARDIN, 1991), optou-se pela análise por categorias e a análise de ocorrências simultâneas.

A análise por categorias funciona a partir de uma segmentação do texto em unidades, seguida de uma classificação dessas unidades em categorias, definidas a priori a partir de uma análise teórica ou induzidas pelo próprio texto. $\mathrm{Na}$ prática, a classificação por temas representa a variante mais popular dessa técnica. A análise de ocorrências simultâneas procura estudar as presenças (ou as ausências) de diferentes elementos em uma unidade do texto, isto é, em um fragmento de texto previamente definido. A frequência das ocorrências é indicativa da associação ou dissociação dos elementos no discurso do entrevistado.

A análise de ocorrências simultâneas é a técnica utilizada pelo programa ALCESTE® na análise de dados textuais (REINERT, 1990).

O software divide o conteúdo das entrevistas em unidades de contexto 
elementares (u.c.e.), que são segmentos de discurso que caracterizam o contexto da unidade de registro que, neste caso, é a palavra. A partir daí, o software busca agrupar as u.c.e. em classes de discurso.

\section{Resultados e discussão}

Foram identificadas duas classes de conteúdo, as quais foram denominadas: $1^{a}$ Violência/perspectiva social e política, composta por $54.49 \%$ das U.C.E. (unidades de contexto elementares) e a $2^{\mathrm{a}}$ Violência/ perspectiva familiar composta por $45.51 \%$ das U.C.E. (unidades de contexto elementares).

\section{Classe 1}

Conforme pode ser visualizado na figura1, a classe 1, denominada VIOLÊNCIA: PERSPECTIVA SOCIAL E POLÍTICA é composta por três subclasses: conceito, causas e enfrentamento/prevenção.

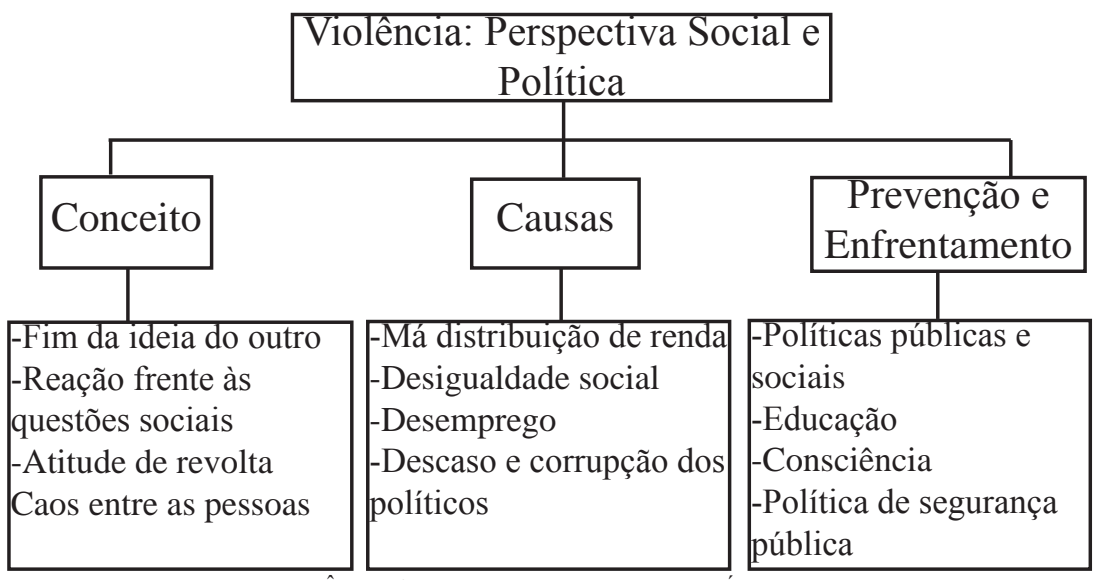

FIGURA 1 - CLASSE 1 - VIOLÊNCIA/PERSPECTIVA SOCIAL E POLÍTICA 
No que se refere ao conceito da violência, que revela a compreensão do fenômeno por parte dos pesquisados, os estudantes tiveram dificuldades em conceituar, dada a diversidade de sentidos desse assunto. Sabiam os tipos de violência da sociedade atual, como violência física, (mais mencionada), psicológica, simbólica e outras. Os conceitos organizados pelos estudantes na referida subclasse representam bem algumas facetas da violência em seu contexto atual. O elemento fim da ideia do outro, por exemplo, mostra as rupturas nas relações sociais, o individualismo e narcisismo que permeiam as trocas. Nesse sentido, a violência traz a marca de uma subjetividade arrebentada, esmagada, frustrada. Essa ideia vai ao encontro com o que é apontado por Wierviorka (1997) que afirma que a violência é capaz de emergir na interação ou no choque das subjetividades negadas ou destruídas.

O elemento fim da ideia do outro pode ser ilustrado na seguinte fala:

"Eu entendo que a violência é como se a barreira que existe entre uma pessoa e outra, entre eu e o outro acabasse. E há uma invasão do outro,[...]. Quando o outro passa a não ter mais, a não existir mais [...] é o fim da ideia do eu e do outro"

Os elementos identificados reação frente às questões sociais, e atitude de revolta podem ser entendidos através da fala de Minayo (2006, p. 17) como sendo "[...] a expressão de crises sociais que levam a população mais atingida negativamente, à revolta frente à sociedade ou ao Estado que não conseguem lhe dar respostas adequadas". E para completar o indivíduo quer participar dos fluxos de consumo conforme Wieviorka (1997) e não participando se sente frustrado e, por sua vez, não reconhecido. Tal reflexão foi identificada por diversos estudantes, entre eles temos:

"[...] a violência é uma reação do que está acontecendo mesmo, das questões sociais que acontecem, que vem junto com a miséria, com a pobreza”;

"[...] a violência pra mim pode ser denominada como atitude de revolta de indivíduo que se sente desvalorizado pela sociedade se sente excluído de alguns padrões que são considerados normais, como ter um bom emprego, ter dinheiro, um bom serviço [...]".

Percebe-se que o núcleo dessas respostas remete à mesma natureza: a violência definida como uma reação frente às deficiências sociais. E diante das deficiências sociais ocorre um Caos entre as pessoas, conforme dito por um estudante da Medicina:

"O fenômeno da violência eu defino como se fosse, assim... um caos entre as pessoas, que tipo é... sofrem, pode ser uma discriminação social que pode gerar uma violência, injustiça social".

Os elementos reação frente às questões sociais, atitude de revolta e caos entre as pessoas se ancoram, portanto, no entendimento da violência produzido a partir de causas sociais. Esses estudantes parecem estruturar suas representações sociais percebendo o quanto o indivíduo é afetado pela dinâmica social e política, 
e que a violência surge, (aqui já se remetendo à segunda subclasse causas) como sintoma do desamparo do Estado, dos prejuízos do sistema capitalista, que geram desigualdades sociais, e da falta de uma política para o bem comum.

As Causas da violência, identificadas na subclasse 2, foram: má distribuição de renda, desigualdade social, desemprego e descaso e corrupção dos políticos.

Têm-se as seguintes falas que ilustram o elemento desigualdade social:

"A principal causa para mim é a desigualdade social. Está tudo numa rede interligada, a questão do desemprego que liga à condição da família, que se liga a educação que as famílias estão dando para os filhos [...]"

"as causas para mim são as injustiças sociais que geralmente atingem a classe menos favorecida, no caso a falta de emprego.

má distribuição de renda:

"[...] vai gerando muita diferença entre as pessoas, não dando oportunidades iguais para cada um. Uns tem muito, cada vez o outro tem menos, e o homem tem um lado instintivo de sobrevivência, é como se a violência entrasse em contato com esse lado instintivo".

No item descaso e corrupção dos políticos, um estudante do Direito elaborou:

"outro fator que causa a violência, o descaso do governo com o povo, a violência do descaso".

Um estudante de Educação Física disse: "corrupção é uma forma de violência, é uma forma de financiamento da violência".

Esses elementos compõem as explicações da violência entendidas por fatores estruturais, ou seja, mecanismos sociais de violência como explicam Capitão e Romaro (2007) em que o sujeito é destituído dos seus direitos em função de como se organiza uma dada sociedade, esses vetores são: a miséria, a desigualdade, o racismo e outros. E na sociedade brasileira, organizada por um contexto social, político, econômico que tem uma constituição histórica de exploração e de dominação desde seus primórdios, tais relações de poder não permitem a emancipação e desenvolvimento de consciência crítica, para que seus cidadãos entendam sua participação enquanto sujeitos de sua história e uma vez sujeitos, agentes de transformação.

Na categoria 3 Prevenção e Enfrentamento foram encontrados os componentes representacionais: Políticas públicas e sociais, educação, consciência e política de segurança pública. Tais respostas estavam em consonância com as causas da violência ditas por eles, aparecendo um vetor diferente, que foi a educação. A educação foi muito mencionada nas duas perspectivas tanto social quanto familiar: uma educação emancipatória, no sentido de consciência crítica de apreensão da realidade, proporcionando ao sujeito um posicionamento mais autêntico em sua esfera pessoal, social e política. Vejam as falas:

"Eu acho que a violência tem que ser enfrentada com políticas púbicas [...] mas na contra mão a isso, se não tiver as políticas públicas sociais englobando 
educação e que a sociedade tenha coisas básicas, não adianta."

"[...] acabar com as injustiças sociais, dar mais oportunidades de emprego para as pessoas que são menos favorecidas, melhorar a saúde".

O item educação apareceu articulado com o de Políticas públicas e sociais, conforme ilustra a fala a seguir:

"Com a educação, com políticas sociais de desenvolvimento, educação na escola, educação da criança pra formar o caráter da criança...”.

As representações acerca da consciência remeteram a uma questão de conhecimento, esclarecimento da realidade. As falas ilustram:

"A compreensão do que significa esse problema da violência, não é só para que tem ensino superior, entender um pouco esse fenômeno, como é gerado, quais são as causas, a natureza da violência, eu acho que as pessoas precisam ter mais consciência do que significa isso, é uma boa forma de se enfrentar a violência"

"Acho que as melhores medidas são políticas públicas, no sentido de educação [...] tem que preparar o cidadão, o indivíduo pra saber se posicionar diante de tudo isso, diante de uma eleição, diante de como se organizar dentro da sua comunidade politicamente".

E por fim o componente Política de segurança pública foi apontado como uma forma de enfrentamento, que engloba tudo que se refere ao combate à impunidade, reforço de policiamento, consciência do papel da polícia, conforme falas abaixo:

"Outra coisa é a punição, a eficácia da punição [...] a punição para a violência tinha que ser mais eficaz, tinha que ser mais rigorosa, é uma forma de prevenção".

Constata-se pelas representações sociais identificadas, que os universitários pesquisados conseguem apreender o contexto sociocultural com todas suas marcas históricas de uma política democrática pouco amadurecida, e em sua maioria mediada pela violência simbólica.

A segunda classe denominada VIOLÊNCIA, PERSPECTIVA FAMILIAR é composta por duas subclasses: Causas e Enfrentamento.

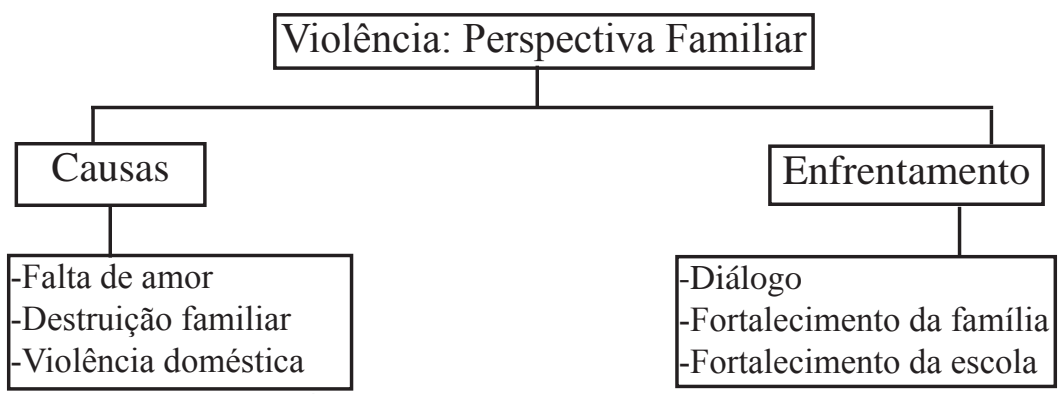

FIGURA 2 - CLASSE - VIOLÊNCIA/PERSPECTIVA FAMILIAR 
Nessa classe, as causas da violência remeteram aos seguintes elementos: falta de amor, desestruturação familiar, violência doméstica. Assim, as representações foram voltadas para aspectos afetivos e familiares, ancoradas em explicações psicológicas e interações microssociais, que se dão no plano das relações familiares, escola, ambiente de trabalho e outros, conforme ilustram as falas a seguir:

"Pode ser pelo estado emocional da pessoa, como ela convive, qual ambiente que ela convive, o ambiente familiar dela, o ambiente de trabalho, a situação, a condição que ela tá, pode gerar violência ... ela vê o pai ou a mãe brigando, ou vê o pai batendo na mãe, a mãe vai lá e bate na criança [...]"

"as causas da violência... acho que é uma falta de formação, de estrutura da pessoa, falta de carinho na infância...".

"A violência eu acredito que ela é formada por cidadãos que é... tem na sua base ali na etapa de sua vida que é quando se forma o caráter dele que é para ter formado com educação, com educação das escolas, tudo, com educação dos pais, isso não é passado para a pessoa para o indivíduo..."

Tais componentes fazem parte de um mesmo contexto de representação social. Muitos estudantes nessa subclasse perceberam o fenômeno da violência no âmbito da violência doméstica, fruto das rachaduras nas relações familiares, dos contextos de falta de amor e de educação, da cadeia da reprodução da violência doméstica, conforme analisa Junqueira (2003, p.25): “[...] no caso da violência na família, em especial na praticada contra crianças e adolescentes, prevalece o autoritarismo, o fato de a criança e o adolescente serem vistos como "coisas" e não como pessoas, ausentes de vontades e desrespeitados em uma necessidade fundamental: o direito à vida com dignidade". Esse tipo de violência é vista pelos pais ou cuidadores como "educação", uma violência que foi banalizada ou naturalizada, ou seja, entendida como "normal", fruto de uma cultura da violência.

Na segunda subclasse denominada Enfrentamento, os componentes diálogo, fortalecimento da família, fortalecimento da escola apareceram articulados. Os estudantes elaboraram representações mostrando que a família e a escola são responsáveis pela formação inicial da personalidade da criança e como enfrentamento seria melhorar essas relações imprimindo uma carga de afetos. As falas que ilustram essas ideias foram:

"Eu vejo que é fazendo o contrário, dando amor ... você tentar ser diferente, mostrar que ele é capaz [...] eu acredito que é você espalhar o amor ... você tentar... se ela nunca teve um abraço, então eu vou dar um abraço".

Outros tantos representaram a família e escola como:

"A educação da família é essencial é raiz, mas ela deve ser complementada na escola, com alguns cursos, em palestras, porque todo mundo é passível a erros, o pai é passível a erros...”.

As respostas indicadas para o enfrentamento foram coerentes com suas causas, uma vez que apontam que no contexto da violência a família está desestruturada, as 
crianças e adolescentes vitimados pelos pais ou familiares, e assim, as medidas de enfrentamento devem estar ligadas ao diálogo, resgate de valores, de afetos, qualidade nas escolas. Segundo Azevedo e Guerra (1993 apud JUNQUEIRA 2003, p 25) "[...] a família é o lugar onde se forma a estrutura psíquica, uma vez que constitui um espaço social distinto, uma vez que gera e consubstancia hierarquias de idade e de sexo, é onde as gerações se confrontam entre si e definem as diferenças e relações de poder". E essas relações de poder muitas vezes são mediadas pela violência simbólica, como mostra Bourdieu (1974 apud SOUZA 2007, p.76), que atua no sentido de "naturalizar", através das instituições, as representações sociais dominantes. Essas ideias são formuladas e espalhadas pelos agentes de dominação, sobretudo pelas instituições escolares. E a família como instituição pode atuar também como agente da violência como, foi representada pelos estudantes.

\section{Considerações finais}

Nesse trabalho exploratório pode-se observar que as representações sociais fazem parte do cenário próprio desses estudantes. Muitos discursos evidenciam saberes científicos apreendidos, e os sentidos construídos por eles não se modificaram muito pelas diferenças de áreas, sendo que 15 dos 20 alunos entrevistados identificaram o vetor social como estruturante da violência. Desses 15, sete entre eles reconheceram também a violência pelo aspecto da família, somente 4 entrevistas abordaram exclusivamente a violência familiar ou outros aspectos.

Nas respostas dos estudantes de Psicologia e dos de Serviço Social houve uma proximidade de sentido, o que denota representações que foram partilhadas. Os aspectos partilhados envolviam os fatores estruturais da violência, como desigualdade social, má distribuição de renda, desorganização do Estado, desemprego e outros. Esses dois cursos possuem disciplinas em comum, como a Psicologia Social que pode ter dado ancoragem e identificação às suas explicações. Os estudantes elaboraram representações circunscrevendo a violência advinda desses fatores estruturais, identificando-a como um sintoma ou causa frente às mazelas sociais. Não trabalharam muito as manifestações objetivas da violência, mas, identificaram os aspectos simbólicos, apesar de não nomear como simbólico, conteúdos relacionados com as relações de poder, dominação, desenvolvimento de consciência crítica. Como enfrentamento, enfatizaram as políticas públicas e sociais associadas com a educação.

O grupo que se voltou para a perspectiva familiar representou a violência em sua dimensão objetiva, direta ou indireta, relacionada à agressividade, dano físico, moral, ou psicológico. Essa violência é fruto do desequilíbrio da família e de sua baixa quali- 
dade de vida, que se intensifica com os problemas sociais. Definiam e representavam a violência como violência doméstica, física, moral, psicológica, sendo gerada pela falta de amor, carinho, respeito, falta de estrutura psicológica, negligência. Nesse grupo misturaram todos os cursos, não sendo exclusivo de nenhuma área acadêmica.

Os estudantes apostam na escola como local privilegiado de transformação e de desenvolvimento, e acreditam que com uma política educacional de valorização da educação, de melhores condições de ensino, a violência diminuiria.

Enfim, quase todos os estudantes puderam representar a violência, e entender que é preciso se unir para a superação desse problema, podendo usar da profissão para se trabalhar com a consciência das pessoas e desenvolver representações sociais que favoreçam o desenvolvimento humano.

\section{REFERÊNCIAS}

ANCHIETA, V. C. C.; GALINKIN, A. L. Policiais civis: representando a violência. Psicologia Social, Porto Alegre, v. 17, n. 1.2006. Disponível em: <http://www.scielo.br/ scielo. php?script=sci_arttext\&pid=S0102-71822005000100005\&lng=en\&nrm=iso $>$. Acesso em: 28/01/2008.

AZEVEDO, M. A; GUERRA, V.N de A. Notas para uma teoria crítica da violência familiar contra crianças e adolescentes In: AZEVEDO, M. A.; GUERRA, V. N. de. A.. Infância e violência doméstica: fronteiras do conhecimento. São Paulo: Cortez, 1993.

BARDIN, L. L'analyse de contenu. 60 ed. Paris: Presses Universitaires de France, 1991.

CAPITÃO, C. G; ROMARO, R. A (Orgs). As faces da violência: aproximações, pesquisas e reflexões. São Paulo: Vetor, 2007.

CASTRO et al. Cultivando Vidas, desarmando violências. Brasília: UNESCO.2001.

CHAMON, E. M. Q. O. Representação social da pesquisa e da atividade científica: um estudo com doutorandos. Estudos de Psicologia, Natal, UFRN, v. 12, p. 37-46, 2007.

DOISE, W. L'ancrage dans les études sur les représentations sociales. Bulletin de psychologie, XLV, n. 405, p. 189-195, 1992.

ELEJABARRIETA, F. Le concept de représentation sociale. In: DESCHAMPS, J.-C.; J.-L. BEAUVOIS, J.-L. (Ed.). Des attitudes aux attributions. Sur la construction de la réalité sociale. Grenoble: Presses Universitaires de Grenoble, 1996. p. 136-150. 
GUARESCHI, N. M. de F.; WEBER, A.; COMUNELLO, L. N.; NARDINI, Milena. Discussões sobre violência: trabalhando a produção de sentidos. Psicologia: Reflexão e Crítica, Porto Alegre, v. 19, n. 1, 2007. Acesso em 8/10/ 2007.

JODELET, D. Représentations sociales: un domaine en expansion. In: JODELET, D. (Ed.). Les représentations sociales. Paris: Presses Universitaires de France, 1989. p. 31-61.

JODELET, D. Représentation sociale: phénomènes, concept et théorie. In: MOSCOVICI, S. (Ed.). La psychologie sociale. 4. ed. Paris: Presses Universitaires de France, 1992. p. 357-389.

JUNQUEIRA, M. F. R. Representação social da violência doméstica contra crianças e adolescentes. Dissertação (Mestrado em Psicologia) - Faculdade de Psicologia, Universidade Católica de Goiás, Goiás, 2003.

MINAYO, M.C. S. O conceito de Representações Sociais dentro da Sociologia Clássica. In: GUARESCHI, P. A; JOVCHELOVITCH, S. (Orgs). Textos em representações sociais. 2.ed. Rio de Janeiro: Vozes, 1995, p.108, 110.

. Violência e Saúde. 20 ed. Rio de Janeiro: FioCruz, 2006.

MOSCOVICI, S. Representações sociais: Investigações em Psicologia Social. Tradução : Pedrinho Guareschi. Petrópolis:Vozes, 2003.

REINERT, M. ALCESTE. Une méthodologie d'analyse de données textuelles et une application: Aurélia de Gérard de Nerval. Bulletin de Méthodologie Sociologique, n. 26, p. 24-54, 1990.

SOUZA, Marcos Santana de. Representações sociais, polícia e violência: um estudo sobre a violência policial. Scientia Plena, v. 3, n. 5, 2007. Disponível em: <www. scientiaplena.org.br/sp-v3n5p75_82.pdf>. Acesso em: 16/01/2008.

WIEVIORKA, M. O novo paradigma da violência. Tempo Social: Revista de Sociologia da USP, n. 9, p.5-6, 1997.

Texto recebido em 02 de março de 2009.

Texto aprovado em 21 de maio de 2009. 